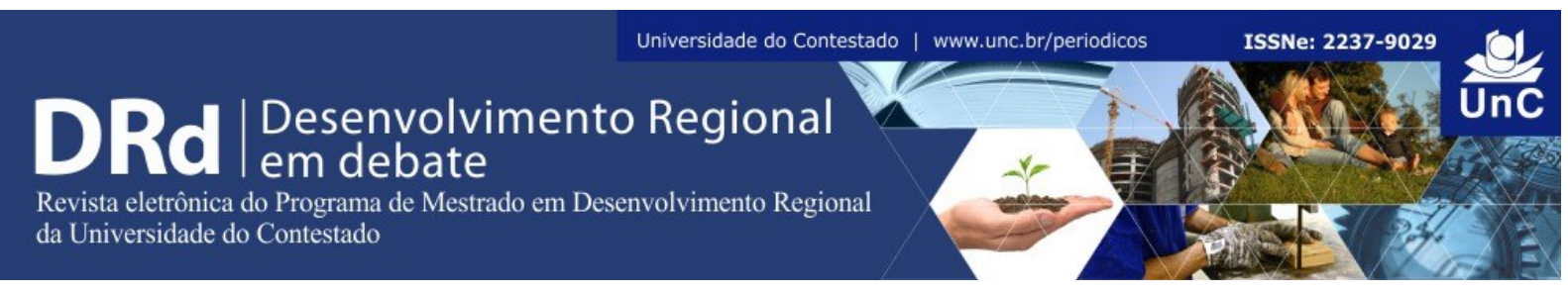

\title{
A FORMAÇÃO DE REDES INTERORGANIZACIONAIS PARA O DESENVOLVIMENTO REGIONAL
}

\author{
Méroli Saccardo dos Santos ${ }^{1}$ \\ Rógis Juarez Bernardy ${ }^{2}$
}

\begin{abstract}
RESUMO
A pesquisa versa sobre a construção de redes interorganizacionais e o papel de uma Instituição de ensino técnico e superior no desenvolvimento regional. O objetivo é analisar a formação de redes interorganizacionais e a importância da atuação do Instituto Federal de Educação, Ciência e Tecnologia do Rio Grande do Sul (IFRS) campus Erechim (RS), para o desenvolvimento regional. A pesquisa justifica-se, pois se propõe observar a interação da Instituição de ensino com os atores sociais regionais e de que forma as áreas de pesquisa contribuem com a região do Alto Uruguai (RS), considerada periférica no contexto socioeconômico do Rio Grande do Sul. Insere-se em uma abordagem descritiva com enfoque de pesquisa qualitativa e a estratégia de pesquisa se enquadra como estudo de caso único, com base no IFRS e suas respectivas redes interorganizacionais, independentemente de sua densidade. As técnicas de coleta de dados foram a pesquisa documental e a base de dados de pesquisa do IFRS. Após a coleta de dados utilizou-se a análise de conteúdo. A Instituição contribui para o desenvolvimento regional, além da incorporação de valor agregado de conhecimento na qualificação de recursos humanos. A formação de redes interorganizacionais poderia intensificar a eficácia de sua atuação na região do Alto Uruguai (RS). Mesmo verificando a forte interação da Instituição com demais atores regionais e a presença de uma rede formal constituída, com o auxílio do IFRS, o tempo de atuação da Instituição pode ser um limitador para a criação de redes interorganizacionais que promovam o desenvolvimento regional.
\end{abstract}

Palavras chave: Desenvolvimento Regional. Ensino Técnico e Superior. Redes Interorganizacionais.

\footnotetext{
${ }^{1}$ Mestre em Administração pela Universidade do Oeste de Santa Catarina - UNOESC (2016) - Servidora pública do Instituto Federal de Educação, Ciência e Tecnologia do Rio Grande do Sul -Campus Sertão. Sertão. Rio Grande do Sul. Brasil. E-mail: meni.s@hotmail.com

${ }^{2}$ Doutor em Cadastro Técnico Multifinalitário e Gestão Territorial - UFSC - Professor da Universidade do Oeste de Santa Catarina (UNOESC). Chapecó. Santa Catarina. Brasil. E-mail: rogis.bernardy@unoesc.edu.br.
}

DRd - Desenvolvimento Regional em debate (ISSNe 2237-9029) 


\title{
THE FORMATION OF INTERORGANIZATIONAL NETWORKS FOR REGIONAL DEVELOPMENT
}

\begin{abstract}
The research deals with the construction of interorganizational networks and the role of an institution of technical and higher education in regional development. The objective is to analyze the formation of interorganizational networks and the importance of the action of the Federal Institute of Education, Science and Technology of Rio Grande do Sul (IFRS) campus Erechim (RS), for regional development. The research is justified because it is proposed to observe the interaction of the educational institution with the regional social actors and how the research areas contribute to the region of Alto Uruguai (RS), considered peripheral in the socioeconomic context of Rio Grande do Sul. The paper works with a descriptive approach with a qualitative research focus and the research strategy is framed as a single case study, based on the IFRS and its respective interorganizational networks, regardless of their density. The techniques of data collection used are the documentary research and the search database of the IFRS and the content analysis was used to treatment and exposition of the data. The Institution contributes to the regional development, besides the incorporation of added value of knowledge in the qualification of human resources. The formation of interorganizational networks should intensify the effectiveness of its activities in the region of Alto Uruguay (RS). Despite the strong interaction of the Institution with other regional actors and the presence of a formal network constituted with the institutional support of the IFRS, the Institution's atuaction time may be a limiting factor for the creation of interorganizational networks that promote the development regional.
\end{abstract}

Keywords: Interorganizational Networks. Regional Development. Technical and Higher Education.

\section{INTRODUÇÃO}

Com o advento da globalização e o aumento da competitividade entre os territórios, a educação técnica e superior surgiu como um dos instrumentos capazes de impulsionar o desenvolvimento das regiões, mesmo que localizadas em ambientes periféricos. Esta modalidade de ensino possui maior capacidade de integração social ao trabalho, pela formação direcionada e pela capacidade de atender as demandas regionais mais imediatas, em relação à inserção no mercado de trabalho.

Neste contexto, o Instituto Federal de Educação, Ciência e Tecnologia do Rio Grande do Sul - Campus Erechim, bem como outros Institutos Federais de Educação, Ciência e Tecnologia, fazem parte do Plano de Expansão da Rede Federal de Educação Profissional e Tecnológica, para ampliar e interiorizar a oferta de educação técnica e tecnológica, por meio da Rede Federal de Educação Profissional e Tecnológica (EPT), com a finalidade de avançar na redução das desigualdades regionais a partir da aproximação destas instituições com o sistema produtivo local e regional (BRASIL, 2008).

Considerando que, para atender suas finalidades, o IFRS necessita interagir com vários

DRd - Desenvolvimento Regional em debate (ISSNe 2237-9029) 
atores sociais pertencentes a suas redes de relações, este estudo tem como propósito analisar a importância da formação de redes interorganizacionais, para o desenvolvimento regional, na área de atuação do IFRS Campus Erechim (RS), além de contribuir tanto para os resultados institucionais quanto para o desenvolvimento da região Alto Uruguai do Rio Grande do Sul.

Resende (2013) ressalta, que a heterogeneidade regional brasileira é marcante e persistente há décadas, visto que as diversidades na formação histórica, social, econômica e climática são as principais contribuintes para a formação das disparidades entre as regiões. Neste sentido, as políticas regionais devem ser desenvolvidas em todos os níveis de governo e estarem focadas nos fatores que causam as desigualdades entre as regiões, intervindo por meio de propostas que reduzam tais disparidades de forma estrutural e contínua.

Estas disparidades podem ser chamadas assimetrias regionais, que são traduzidas em diferentes níveis de desenvolvimento econômico e social, e induzem aos processos de vulnerabilidade das regiões (MORAIS, 2011). Para reduzir os efeitos destas destaca-se a aplicação de políticas de desenvolvimento regional, na área de educação, especialmente a educação superior e técnica. De acordo com Bispo e Santos Junior (2013), por meio da educação superior e técnica é possível que as pessoas conquistem melhores posições no mercado de trabalho, obtenham crescimentos potenciais em seus rendimentos e contribuam para gerar o desenvolvimento do país. Para os autores, as maiores responsáveis pelas desigualdades de renda, níveis de pobreza e trabalho, são as diferenças em educação. Acrescenta-se que, além da dificuldade de superar outros entraves, como o desenvolvimento tecnológico, a inovação, o empreendedorismo, existe o potencial para a formação de parcerias interinstitucionais, com base na cooperação de diferentes agentes de desenvolvimento em prol de objetivo comum, sendo que nessa seara, reside a oportunidade desta pesquisa.

No documento de referência da I Conferência Nacional de Desenvolvimento Regional (BRASIL, 2012), está o desafio de melhorar o ensino em todos os níveis, para que seja capaz de desenvolver pessoas com capacidade elevada de aprendizagem e com espírito crítico de cidadania. Desta forma, esta pesquisa tem relevância na medida em que se propõe a analisar a interação da Instituição com os atores sociais regionais, como potencial impulsionador do desenvolvimento, bem como verificar como as áreas de ensino e pesquisa do Campus Erechim, contribuem com o desenvolvimento da região do Alto Uruguai (RS), considerada periférica, no contexto socioeconômico do Estado. Neste contexto, verifica-se como se estruturam e denotam modos de coordenação, cooperação, diferenciação e integração entre unidades organizacionais especializadas, com base no IFRS.

De acordo com Cândido (2002, p. 14), para que ocorra o desenvolvimento regional é necessário que o Estado, além de criar um ambiente favorável à inovação, conte "[...] com atores chave para a geração do desenvolvimento, quais sejam: as empresas, as redes produtivas, às associações, as instituições de apoio e a sociedade civil", estabelecendo assim, a formação de redes de desenvolvimento. Esses atores, que incluem instituições de ensino técnico e superior, como o IFRS, devem desenvolver competências técnicas de forma interativa, atuar por meio de processos de aprendizagem e intercâmbio voltados para um objetivo compartilhado, pois, uma economia baseada no conhecimento, que surge quando as empresas e as instituições interagem, é capaz de alcançar vantagens competitivas específicas e de difícil imitação (ESSER et. al., 1994).

$\mathrm{Na}$ caracterização metodológica se efetivou uma análise dos projetos de ensino e 
pesquisa desenvolvidos no IFRS Campus Erechim (RS), entre 2011 e 2015, sua aplicação e relação com a realidade regional, bem como a sua integração com a realidade social e produtiva no âmbito regional. Além da quantidade de projetos neste período, observou-se a modalidade, potencialidades, vetores de desenvolvimento regional, em conformidade com o referencial teórico, e o vínculo do projeto com a região, acrescido de sua integração com demais projetos.

Deste modo, o estudo parte do desejo de contribuir para o fortalecimento do IFRS Campus Erechim (RS), parte integrante do Plano de Expansão da Rede Federal de Educação Profissional e Tecnológica, por meio de subsídios teóricos e empíricos que possam nortear a instituição no relacionamento com os demais atores sociais da região Alto Uruguai (RS), em prol do desenvolvimento regional.

Por fim, além desta seção introdutória, o artigo é composto pelo referencial bibliográfico, os procedimentos metodológicos, a análise dos resultados e a respectiva conclusão e referências.

\section{APORTES PARA A COMPREENSÃO DO DESENVOLVIMENTO REGIONAL E REDES INTERORGANIZACIONAIS}

O desenvolvimento está vinculado a uma série de elementos que se manifestam no território, de forma que existe uma necessidade de alteração e evolução positiva na qualidade de vida, equidade ambiental e menores assimetrias entre as pessoas, acessos e entre os próprios lugares. Desta forma, pode-se reconhecer que não existe uma uniformidade no desenvolvimento das regiões, tampouco dos indicadores relacionados à qualidade de vida da população, entretanto, distintas manifestações de desenvolvimento são perceptíveis, em diferentes lugares.

Para Perroux (1967), em sua obra clássica, o desenvolvimento consiste em um processo continuo e complexo de mudanças, que envolve transformações econômicas, políticas e sociais. Furtado (2000), corrobora com essa ideia ao evidenciar a existência de dois sentidos distintos de desenvolvimento: um relacionado à evolução do sistema social de produção, por meio do aprimoramento de técnicas que elevam a eficácia e produtividade do conjunto de sua força de trabalho; outro diz respeito à satisfação das necessidades humanas e sua relação com o aumento da expectativa de vida e melhoria de suas condições financeiras.

Sen (2000, p. 54) salienta que o "[...] desenvolvimento pode ser visto como um processo de expansão das liberdades reais que as pessoas usufruem". Desta forma, prioriza a ideia de que a sociedade necessita superar as fontes que limitam as suas liberdades substanciais, como as carências econômicas, sociais e ambientais. Boisier (2006, p. 69) trata o conceito de desenvolvimento como "[...] dependente da autoconfiança coletiva na capacidade de inventar recursos, movimentar aqueles já existentes e agir em forma cooperativa e solidária, desde o próprio território". Já Llorens (2001, p. 81) determina quatro dimensões do desenvolvimento econômico que conduzem a uma melhoria da qualidade de vida da população: econômica, de formação de recursos humanos, sociocultural e político e administrativo.

DRd - Desenvolvimento Regional em debate (ISSNe 2237-9029) 
Para Casarotto e Pires (2001, p. 112-113), as dimensões devem ser consideradas como partes de um todo que mantém continua "[...] interação dentro do processo de relações sociais". Os autores afirmam que tais "[...] dimensões e sua importância foram determinadas pela evolução do conhecimento social e pelas necessidades e prioridades determinadas pelos conjuntos sociais". Esta discussão remete ao entendimento da noção de região em seus diversos sentidos. Lima e Simões $(2009$, p. 1) definem região, “[...] como unidade de análise, representada por um conjunto de pontos do espaço que tenham maior integração entre si do que em relação ao resto do território [...]", portanto, possuem "certa identidade" em relação aos demais espaços que o circundam, podendo ser vinculada à atuação de uma instituição, porque se caracteriza de processos sociais e institucionais.

Para Oprițescu (2012), o conceito de desenvolvimento regional visa estimular investimentos no setor público e privado, para que sejam desenvolvidas atividades econômicas diversificadas que contribuam para a redução do desemprego e melhoria da qualidade de vida das pessoas. Desta forma, "[...] o principal método que pode levar a um desenvolvimento equilibrado das regiões está no financiamento diferenciado destas, de modo que as regiões menos desenvolvidas obtenham proporcionalmente mais fundos do que demais" (OPRIȚESCU, 2012, p. 169), desta forma, se reconhece o impulso externo ou exógeno, como elemento primordial para que estas regiões se desenvolvam.

Albuquerque (2014), defende que inicialmente a noção de desenvolvimento baseava-se na dependência de vantagens competitivas territoriais ou fatores como clima, localização geográfica e provimento de recursos. No entanto, está noção foi gradualmente alterada e atualmente volta-se a atenção para as "vantagens competitivas dinâmicas" desenvolvidas em cada território. Para o autor, tais vantagens são baseadas na construção de estruturas socioinstitucionais e territoriais, a partir da incorporação de valor agregado de conhecimento na qualificação de recursos humanos, para introduzir "[...] inovações produtivas, socioinstitucionais, organizacionais e de gestão, com base na qualidade, diferenciação e sustentabilidade ambiental" (ALBUQUERQUE, 2014, p. 177).

Para Albuquerque (2014), na construção de vantagens competitivas dinâmicas é necessária a intervenção de diferentes atores e os seguintes aspectos: estimulo a acumulação e difusão de conhecimentos adequado ao perfil produtivo de cada território; facilitação das ligações entre o tecido local de empresas e oferta territorial de conhecimentos e assistência técnica; orientação do sistema educativo e formação técnica e profissional de acordo com as necessidades locais e o perfil territorial de produção; incentivo de habilidades criativas e empreendedoras; devem encorajar a formação de redes e a cooperação entre agentes públicos e privados.

Ao defender a colaboração entre as esferas pública, privada e acadêmica Etzkowitz e Leydesdorff elaboraram a teoria da Tríplice Hélice, como propulsora do desenvolvimento regional. Trata-se de um modelo em que à universidade promove, de forma local e regional, relações com o governo e empresas de forma a criar novos conhecimentos, fomentar a inovação tecnológica e fortalecer o desenvolvimento (ETZKOWITZ, 2009). Além disso, Llorens (2001) afirma que a criação de um "entorno territorial inovador" é um dos principais objetivos de iniciativas de desenvolvimento econômico territorial. $\mathrm{O}$ autor destaca aspectos e linhas de políticas fundamentais a serem seguidos: articulação produtiva territorial do tecido empresarial e das diferentes atividades rurais e urbanas; conhecimento das tecnologias apropriadas à dotação de recursos e potencialidades territoriais; atenção à inovação 
tecnológica e organizacional adequadas aos níveis produtivos e empresariais; adaptação do sistema educacional e de capacitação profissional à problemática produtiva e socioterritorial.

Bologa (2010, p. 129), ao determinar que a competitividade é um fator determinante para o desenvolvimento das regiões define como uma das principais fontes, em nível regional, o "[...]capital intelectual [...] resultado da tradição acadêmica e políticas locais para atrair empresas que necessitam de trabalhadores altamente qualificados". Neste sentido, afirma-se a relevância em verificar se o IFRS - Campus Erechim (RS) já faz parte desta tradição acadêmica e se tem contribuído, a partir da formação de recursos humanos qualificados e parcerias, para atrair novos empreendimentos para a região ou quais são as outras formas de desenvolvimento que se manifestam na região em função de sua presença na mesma.

Albuquerque (2014, p. 182) destaca também a importância das redes estruturais de desenvolvimento territorial. Segundo o autor, estas redes são sistemas técnicos que permitem a condução dos fluxos de informação, energia, pessoas, capital e bens, dentre outros recursos. Estas redes mantêm interconexões por meios de estruturas tangíveis, como as vias de comunicações e também as "[...] estruturas intangíveis fundamentais[...]" que asseguram o fluxo de informações territoriais estratégicas por meio destes espaços de encontros e aprendizagem construídos pelos atores. Dentre estas estruturas intangíveis estão as redes de negócios e cooperação tecnológica, redes de comercialização, ou redes para a formação de capital humano. No quadro 1 foram elencados os vetores do desenvolvimento regional, em conformidade com este referencial bibliográfico.

Quadro 1 - Vetores do Desenvolvimento Regional

\begin{tabular}{|c|c|c|}
\hline $\begin{array}{c}\text { Vetores de } \\
\text { Desenvolvimento } \\
\text { Regional } \\
\end{array}$ & Características & Autores de Base \\
\hline $\begin{array}{l}\text { Vantagens competitivas } \\
\text { territoriais }\end{array}$ & $\begin{array}{l}\text { Potencialidades específicas das regiões sejam elas de } \\
\text { localização, de condições climáticas favoráveis, de } \\
\text { provimento de recursos, solos, recursos hídricos e } \\
\text { outros. }\end{array}$ & $\begin{array}{l}\text { Llorens (2001), Vázquez- } \\
\text { Barquero (2005), } \\
\text { Albuquerque (2014). }\end{array}$ \\
\hline $\begin{array}{l}\text { Vantagens competitivas } \\
\text { dinâmicas }\end{array}$ & $\begin{array}{l}\text { Construção de estruturas socioinstitucionais e } \\
\text { territoriais, a partir da incorporação de valor agregado } \\
\text { de conhecimento na qualificação de recursos humanos, } \\
\text { para introduzir inovações produtivas, } \\
\text { socioinstitucionais, organizacionais e de gestão, com } \\
\text { base na qualidade, diferenciação e sustentabilidade } \\
\text { ambiental. }\end{array}$ & $\begin{array}{l}\text { Llorens (2001), } \\
\text { Albuquerque (2014), }\end{array}$ \\
\hline $\begin{array}{l}\text { Políticas fundamentais de } \\
\text { desenvolvimento regional }\end{array}$ & $\begin{array}{l}\text { Políticas públicas que promovem o fortalecimento } \\
\text { socioeconômico regional. }\end{array}$ & Llorens (2001) \\
\hline $\begin{array}{l}\text { Redes } \\
\text { Interorganizacionais }\end{array}$ & $\begin{array}{l}\text { Interação entre os atores públicos e privados na } \\
\text { formulação e implementação de políticas e estratégias } \\
\text { para o alcance de objetivos específicos e coletivos. }\end{array}$ & $\begin{array}{c}\text { Etzkwoitz (2009), Llorens } \\
\text { (2001), Albuquerque } \\
\text { (2014) }\end{array}$ \\
\hline $\begin{array}{l}\text { Redes estruturais } \\
\text { tangíveis e intangíveis }\end{array}$ & Infraestrutura regional, tecnológica e do conhecimento. & $\begin{array}{l}\text { Cooke et. al. (2003), } \\
\text { Albuquerque (2014) }\end{array}$ \\
\hline
\end{tabular}

Fonte: Elaborado pelos autores. 


\subsection{FORMAÇÃO DE REDES INTERORGANIZACIONAIS}

Dentre os sentidos comumente utilizados de redes estão o de proteção e de sustentação; o de denotação da ideia de fluxo ou circulação (redes de comunicação e interconexão) e o de entrelaçamento de fios que formam um tecido. Neste último caso, se aplicado no estudo das organizações, os fios correspondem às relações entre os atores e organizações que por sua vez representam os nós, pontos mais fortes (LOYOLA; MOURA, 1996; SIQUEIRA, 2000; FLEURY; OUVERNEY, 2007).

Dias (2005), ao relacionar os conceitos de rede e território afirma que o território é suporte das redes, e estas são construções sociais. Assim “[...]indivíduos, grupos, instituições ou firmas (organizações) desenvolvem estratégias de toda ordem (políticas, sociais, econômicas e territoriais) e se organizam em rede" (DIAS, 2005, p. 22-23). Para Castells (2002, p. 548), as redes são uma nova forma de organização que em conjunto com a revolução tecnológica e o processo de globalização fazem parte uma nova estrutura social que ele denomina "sociedade em rede".

Nos estudos organizacionais as redes têm sua contribuição como alternativa teórica para compreender as novas e complexas relações entre as organizações e os múltiplos atores que compõem o ambiente em que estão inseridas. Esta compreensão possibilita driblar circunstâncias de incertezas e auxiliar as organizações na sobrevivência, competitividade e promoção do aprendizado social, a partir da construção de redes fortemente vinculadas. A abordagem de redes também pode trazer contribuições partindo da análise da interdependência organizacional, onde as organizações exercem influências sobre outras organizações e demais atores sociais e também são influenciadas por estes (LOYOLA; MOURA, 1996; SIQUEIRA, 2000; BALESTRIN, 2002).

Para Amato Neto (2005), as redes interorganizacionais são uma alternativa para a melhoria da posição competitiva das empresas, principalmente das pequenas e médias, pois estão em desvantagem comparadas às grandes empresas. Isso se deve ao fato de as grandes empresas terem condições de dominar todas as etapas da cadeia de valor, ou seja, suprimentos, logística, pesquisa e desenvolvimento, produção e marketing.

Pode-se afirmar que a formação de redes entre os atores responsáveis pela eficácia do ambiente socioeconômico pode contribuir na conquista de vantagens competitivas e alavancar o processo desenvolvimento (CASAROTTO; PIRES, 2001). Casarotto e Pires (2001, p. 107) afirmam que "[...] a potencialidade básica de qualquer local e região está assentada em sua população, ou mais amplamente, em seu ambiente: a interação dessa gente, por meio de sua cultura, com o território e suas relações externas". Desta forma, considera-se que as redes interorganizacionais fazem parte dos vetores de desenvolvimento e fortalecem outros vetores como os decorrentes das vantagens competitivas territoriais e dinâmicas (ALBUQUERQUE, 2014).

Conforme Nakano (2005, p. 59), “[...] em condições de reciprocidade, uma organização entra em uma rede se possuir algum tipo de recurso (informação, serviço ou produto) que seja de interesse para os demais participantes, de forma que ela própria vai obter recurso de seus parceiros". Além disso, o autor tratar da "estrutura da rede" que se refere à maneira em que os relacionamentos estão dispostos entre as organizações, ou seja, por meio

DRd - Desenvolvimento Regional em debate (ISSNe 2237-9029) 
de relações diretas (fortes) ou indiretas (fracas). Nas relações diretas, as organizações interagem diretamente, sem a presença de intermediários, já nas relações indiretas interagem apenas por intermédio de outras organizações que já mantém vinculo em relações. Desta forma, o IFRS pode contribuir com as organizações da região Alto Uruguai, de forma direta ou indireta, por meio da informação, bem como desenvolvimento de pesquisas, produtos e serviços, pelos profissionais habilitados que são canalizados ao mercado regional.

Assim, têm-se duas vertentes para as redes interorganizacionais, a "da competitividade e a da solidariedade", de forma que se constituem em "[...] agenciamentos polares, mas não excludentes nas políticas de gestão territorial" (FISCHER, 2004, p. 20-21). Com base nas afirmações de Fischer (2004) a pesquisa se utiliza das duas vertentes, tendo em vista que mesmo que em princípio as redes interorganizacionais as quais o IFRS-Campus Erechim faz parte tenham caráter predominante social acabam por fortalecer e incentivar a formação de redes com potencial competitivo, por intermédio das suas atividades de ensino e pesquisa.

Segundo Peci e Costa (2002), para que haja uma situação definida como rede de arranjos interorganizacionais, entre atores públicos e privados, é necessário um novo paradigma de gestão. A interação entre os atores na formulação e implementação de políticas públicas deve ser fundamentada em uma gestão integrada das organizações, para o alcance de objetivos específicos e coletivos. A participação dos membros desde o levantamento das necessidades, formulação estratégica, execução de ações e avaliação dos resultados constituise em aspecto central das redes interorganizacionais (PECI; COSTA, 2002).

Em se tratando das instituições públicas de ensino técnico e superior a formação de estruturas de redes interorganizacionais formais ou informais deve ser incentivada. Como agentes de políticas públicas de ensino e pesquisa (extensão), estas instituições fazem parte do processo de desenvolvimento do país, a partir de ações regionais e locais. E sem a adoção de uma estrutura e gestão integrada com os demais atores sociais sua ação é dificultada e pode não surtir o efeito almejado diante da diversidade de fatores a serem analisados na atual conjuntura socioeconômica.

\subsection{AS INSTITUIÇÕES DE ENSINO TÉCNICO E SUPERIOR NO DESENVOLVIMENTO DAS REGIÕES}

A partir do cenário atual da educação no Brasil e analisando as políticas de ensino vigentes pode-se inferir que a fase atual do ensino é de erradicação do analfabetismo de pessoas em idade escolar, avanço e qualificação dos sistemas de ensino e ampliação da formação profissional (BRASIL, 2014). Neste sentido, os Institutos Federais de Educação Ciência e Tecnologia são utilizados como ferramentas do governo, para difusão do conhecimento, pesquisa e desenvolvimento, inclusive em regiões periféricas, mediante atuação integrada e regionalizada de transformação socioeconômica (AMARAL; FERREIRA; LACERDA, 2009).

Em um ambiente de economia globalizada, o desenvolvimento dos potenciais econômicos regionais, é visto como fundamental para combater as desigualdades e aumentar a competitividade das regiões. As instituições de ensino técnico e superior, por meio da

DRd - Desenvolvimento Regional em debate (ISSNe 2237-9029) 
capacitação dos indivíduos, pesquisa e extensão e construção de condições necessárias ao aproveitamento das potencialidades regionais, passam a desempenhar papel estratégico na busca pela competitividade das regiões onde se inserem, são consideradas como instrumentos essenciais ao processo de desenvolvimento das regiões (SERRA; ROLIM, 2013).

No Brasil, as políticas nacionais de desenvolvimento regional, corroboram com esta concepção e posiciona a educação, em todos os níveis, inclusive à básica, como o caminho para a competitividade do país. No entanto, para que a educação cumpra este papel, desafios como à melhora da qualidade do ensino, ampliação do acesso à educação, assim como a expansão do ensino técnico, tecnológico e a formação em nível superior, precisam ser consolidados (BRASIL, 2012).

Fernandes (2007), ao tratar especificamente do ensino superior, relata que instituições deste nível podem ter impactos positivos, tanto de ordem econômica quanto social, no desenvolvimento das regiões. Isso se deve ao fato dessas serem mecanismos fundamentais de desenvolvimento regional capazes de impulsionar oportunidades educacionais, econômicas, sociais e culturais. A presença de instituições de ensino superior, pelo aporte que possuem em relação à geração de trabalho, renda, inovação e diversificação econômica, entre outras, pode ser considerada como um vetor de desenvolvimento.

De acordo com Boucher, Conway e Van Der Meer (2003), as instituições de ensino superior desempenham papeis no desenvolvimento das regiões: contribuintes econômicos, na medida em que são empregadoras, pagadoras de salários, consumidoras de produtos e serviços das empresas locais e atraentes de estudantes que também movimentam a economia local por meio do consumo. O papel de mercantilizadoras do conhecimento produzido nestas instituições, por meio de direitos de propriedade intelectual, transferência de tecnologia, parques científicos e spin-off participação formal e informal como um ator institucional, em conjunto com outros atores regionais, em ligações e redes de aprendizagem, inovação e governança.

A região de estudo, o Alto Uruguai (RS), possui estruturas históricas e culturais favoráveis à indústria, pois conforme aponta os estudos de Rosa (2008) à região foi colonizada por imigrantes de diversas etnias, o que concebeu um bom nível de diversidade cultural e a herança da cultura fabril europeia trazida por estes imigrantes. "A cultura fabril foi transmitida entre gerações e o resultado é que a indústria constitui uma das principais forças da região do Alto Uruguai”. (ROSA, 2008, p. 51). A indústria da região é diversificada, contando com alimentícias, metalmecânica, têxteis e de vestuário, de móveis, de couros e calçados dentre outras, entretanto, se apresenta espacialmente concentrada em Erechim (RS), o que determina igual concentração das oportunidades de trabalho e de geração de renda, contribui para a formação de um polo regional.

Outro fator diz respeito à consorciação entre os setores econômicos e públicos, como exemplo cita-se o agroindustrial, o segmento de serviços, como suporte às atividades industriais. Na região do Alto Uruguai (RS) podem ser mencionadas como redes ou formas associativas vinculadas ao desenvolvimento regional: o Conselho Regional de Desenvolvimento Norte (COREDE), a Associação de Municípios do Alto Uruguai (AMAU), a Metal-Mecânica Rede do Alto Uruguai Gaúcho e, mais recentemente, o Arranjo Produtivo Local - APL Têxtil e Vestuário do Alto Uruguai Gaúcho - APL Polovest. Desta forma, as atividades econômicas também são indicadoras de desenvolvimento e recebem aporte das 
instituições de ensino pelas funções diversificadas que possuem na região.

Por fim, o governo vem tomando iniciativas para fortalecer a capacidade tecnológica da indústria (e demais setores produtivos), propiciando um ambiente legal e institucional favorável ao investimento das empresas em atividades de pesquisa e desenvolvimento conjuntamente com as instituições de ensino (Tríplice Hélice). Os desafios propostos pelo governo para as universidades, sem deixar de valorizar seu papel elementar de formação de recursos humanos e realização atividades de pesquisa, é de transferir tecnologia para a indústria, comercializar o conhecimento e promover o empreendedorismo, a fim de responder às exigências econômicas e sociais em nível local e regional (MACULAN; MELLO, 2009).

\section{PROCEDIMENTOS METODOLÓGICOS}

O estudo abordou, à luz de abordagens do desenvolvimento regional e das redes interorganizacionais, a análise da formação de redes interorganizacionais para o desenvolvimento da região Alto Uruguai (RS), a partir da atuação do IFRS Campus Erechim (RS), nesta região. Desta forma, foram coletados dados referentes à atuação da instituição, no que diz respeito as suas atividades de ensino e pesquisa, entre o período de 2011 (primeira série de dados) até 2015. Para isso, o universo desta pesquisa se restringiu ao contexto regional em que está inserida a instituição, ou seja, na análise da relação da instituição com atores sociais, principalmente do setor produtivo.

A delimitação do período escolhido deve-se a dois motivos: i) 2011 foi o primeiro ano em que IFRS - Campus Erechim teve registro de suas atividades - os projetos começaram a ser cadastrados neste ano; ii) 2015, no mês de dezembro é o tempo limite em que existem dados disponibilizados em período de 12 meses.

Quanto à abordagem da pesquisa classifica-se como qualitativa por considerar que esta abordagem é necessária e adequada ao propósito do estudo. A pesquisa qualitativa pode ser caracterizada por "[...] estudar os fenômenos que envolvem os seres humanos e suas intrincadas relações sociais, estabelecidas em diversos ambientes" (GODOY, 1995, p. 21), ou seja, nas ciências sociais a pesquisa qualitativa trabalha com um conjunto de fenômenos humanos composto do "[...] universo dos significados, dos motivos, das aspirações, das crenças, dos valores e das atitudes" (MINAYO, 2010, p. 21). No caso desta pesquisa, a abordagem qualitativa foi orientada a partir da seleção e análise da base de dados da Instituição IFRS, chamada de SIGProj.

Como método ou estratégia de pesquisa optou-se pelo estudo de caso único integrado, tendo em vista que o objeto a ser pesquisado pode ser considerado um fenômeno contemporâneo, além da necessidade de se utilizar múltiplas fontes de pesquisa, podendo-se trabalhar evidências qualitativas (YIN, 2010). O estudo de caso é considerado um dos tipos de pesquisa qualitativa que permite "[...] fornecer o conhecimento aprofundado de uma realidade delimitada que os resultados atingidos podem permitir o encaminhamento de outras pesquisas" (TRIVIÑOS, 2011, p. 111) e "[...] preservar as características holísticas e significativas dos eventos da vida real como o comportamento dos grupos, os processos organizacionais e administrativos" (YIN, 2010, p. 24). 
Neste sentido, esta pesquisa utilizou como fonte de dados o Sistema de Informação e Gestão de Projetos - SIGProj, para consulta dos projetos de pesquisa do IFRS - Campus Erechim (RS), os vínculos destes com as matrizes econômicas regionais, vetores de desenvolvimento local e regional alavancados e atores participantes dos projetos.

Além disso, buscou-se a convergência das diferentes evidências confrontadas com a abordagem teórica balizadora da pesquisa, o que pode ser observado na análise dos projetos de pesquisa cadastrados no SIGProj. As informações encontradas no sistema foram organizadas em forma de quadro síntese e analisados todos os projetos cadastrados entre 2011 e 2015 (em 2010 ainda não existiam projetos) quanto aos vetores de desenvolvimento local e regional alavancados pelos projetos, quanto aos vínculos dos projetos com as atividades regionais e também identificados as instituições e os atores sociais participantes dos projetos.

Desta forma, a análise dos resultados desta pesquisa está centrada na integração das informações da base de dados do SIGProj, visando à cristalização da compreensão da realidade organizacional em torno das redes que se formam a partir da presença do Instituto Federal do Rio Grande do Sul, unidade de Erechim (RS).

\section{APRESENTAÇÃO E ANÁLISE DOS DADOS}

Os projetos de pesquisa cadastrados no SIGProj, do IFRS, campus de Erechim (RS), entre 2011 e 2015, foram avaliados sob a ótica da modalidade, suas potencialidades, vetores de desenvolvimento regional, em conformidade com o aporte bibliográfico desta pesquisa e o vínculo com a região. Os projetos do IFRS de 2011 podem ser vistos no quadro 2.

Quadro 2 - Projetos de Pesquisa cadastrados no SIGProj - 2011

\begin{tabular}{|c|c|c|c|c|}
\hline $\begin{array}{c}\text { Quanti- } \\
\text { dade }\end{array}$ & $\begin{array}{c}\text { Modalidade } \\
\text { do Projeto }\end{array}$ & Potencialidades & $\begin{array}{c}\text { Vetores de } \\
\text { desenvolvimento regional }\end{array}$ & $\begin{array}{c}\text { Vínculo do Projeto com a } \\
\text { Região }\end{array}$ \\
\hline 01 & $\begin{array}{c}\text { Ensino } \\
\text { Técnico e } \\
\text { superior }\end{array}$ & $\begin{array}{c}\text { Aplicação com os } \\
\text { discentes dos cursos } \\
\text { IFRS - Erechim e Porto } \\
\text { Alegre (RS) }\end{array}$ & $\begin{array}{c}\text { Políticas fundamentais de } \\
\text { desenvolvimento regional }\end{array}$ & $\begin{array}{c}\text { Instituição de Ensino } \\
\text { Técnico e Superior } \\
\text { (Erechim e Porto Alegre) }\end{array}$ \\
\hline 05 & $\begin{array}{c}\text { Dinâmica } \\
\text { econômica } \\
\text { regional }\end{array}$ & $\begin{array}{c}\text { Aplicação junto aos } \\
\text { agricultores feirantes, } \\
\text { indústria têxtil e } \\
\text { alimentar }\end{array}$ & $\begin{array}{c}\text { Vantagens competitivas } \\
\text { dinâmicas }\end{array}$ & $\begin{array}{c}\text { Instituição de Ensino } \\
\text { Técnico e Superior } \\
\text { Agricultores e industriários }\end{array}$ \\
\hline 04 & $\begin{array}{c}\text { Contemplação de } \\
\text { discentes do IFRS e } \\
\text { Rede de Indústrias } \\
\text { Inotalmecânica do Alto } \\
\text { Uruguai }\end{array}$ & $\begin{array}{c}\text { Vantagens competitivas } \\
\text { dinâmicas }\end{array}$ & $\begin{array}{c}\text { Instituição de Ensino } \\
\text { Técnico e Superior e rede } \\
\text { de indústrias }\end{array}$ \\
\hline 01 & $\begin{array}{c}\text { Marketing e } \\
\text { varejo }\end{array}$ & $\begin{array}{c}\text { Satisfação dos } \\
\text { consumidores do } \\
\text { comércio de Erechim }\end{array}$ & Vantagens competitivas \\
dinâmicas & $\begin{array}{c}\text { Instituição de Ensino } \\
\text { Técnico e Superior, } \\
\text { comerciantes e público } \\
\text { consumidor regional }\end{array}$ \\
\hline
\end{tabular}

Fonte: SIGProj - IFRS Campus Erechim (RS), 2011.

Adaptação: Autores

DRd - Desenvolvimento Regional em debate (ISSNe 2237-9029)

v. 9, p. 140-159, 2019. 
Nos onze projetos de pesquisa cadastrados em 2011, verifica-se uma maior preocupação com o desenvolvimento da indústria e agroindústria local, principais matrizes econômicas da região, de forma a proporcionar a ampliação de vantagens competitivas dinâmicas nestas atividades. Vantagens essas que, de acordo com Albuquerque (2014), podem ser construídas a partir da incorporação de valor agregado de conhecimento na qualificação de recursos humanos. Todos os projetos possuem vínculo com as atividades econômicas desenvolvidas na região do Alto Uruguai (RS), e a maioria deles, contempla atores socioeconômicos como indústrias, agroindústrias, empresas do comércio, agricultores e também consumidores.

Não se verifica nestes projetos, ou a partir deles, a formação efetiva ou formal de redes interorganizacionais, ou seja, não existe a interdependência organizacional entre os atores sociais conforme evidenciado por Loyola; Moura (1996); Siqueira (2000) e Balestrin (2002). No entanto, houve a interação da instituição com outros atores sociais regionais, ou seja, uma cooperação solidária (BOISIES, 2006). Constata-se que os estudos, apesar de isolados, estão alinhados com o desenvolvimento das atividades econômicas locais e regionais e focam, de diferentes formas, na sustentabilidade das organizações da região. Este se processa por meio da diversificação das atividades produtivas, agregação de valor à produção, melhorias de processos de gestão, produção e vendas, aumento de competitividade, dentre outras formas vinculadas às atividades regionais.

Infere-se que, as relações do campus Erechim (RS) com os atores socioeconômicos mencionados são diretas e informais de cunho social, onde o papel do IFRS está direcionado para a promoção do empreendedorismo, inovação e aplicação de conhecimentos no desenvolvimento de potenciais econômicos, em conformidade com o aporte teórico de Etzkowitz (2009). Os demais projetos, onde não existe contemplação de atores externos à instituição, possuem caráter inovativo de desenvolvimento tecnológico, também direcionado à indústria têxtil e metalmecânica. A seguir são apresentados no quadro 3 os projetos de pesquisa cadastrados no Sigproj no ano de 2012.

Quadro 3 - Projetos de Pesquisa cadastrados no SIGProj - 2012

\begin{tabular}{|c|c|c|c|c|}
\hline $\begin{array}{c}\text { Quanti- } \\
\text { dade }\end{array}$ & $\begin{array}{c}\text { Modalidade } \\
\text { do Projeto }\end{array}$ & Potencialidades & $\begin{array}{c}\text { Vetores de desenvolvimento } \\
\text { regional }\end{array}$ & $\begin{array}{c}\text { Vínculo do Projeto } \\
\text { com a Região }\end{array}$ \\
\hline 02 & $\begin{array}{c}\text { Ensino e } \\
\text { cidadania }\end{array}$ & $\begin{array}{c}\text { Aplicação com o público } \\
\text { interno do IFRS, deficientes } \\
\text { visuais e rede de ensino } \\
\text { básica }\end{array}$ & $\begin{array}{c}\text { Vantagens competitivas } \\
\text { dinâmicas }\end{array}$ & $\begin{array}{c}\text { Instituição de Ensino } \\
\text { Técnico e Superior e } \\
\text { comunidade externa }\end{array}$ \\
\hline 01 & $\begin{array}{c}\text { Dinâmica } \\
\text { econômica } \\
\text { regional }\end{array}$ & $\begin{array}{c}\text { Aplicação na indústria } \\
\text { têxtil regional }\end{array}$ & Vantagens competitivas & $\begin{array}{c}\text { Instituição de Ensino } \\
\text { Técnico e Superior e } \\
\text { indústria têxtil }\end{array}$ \\
\hline 01 & Inovação & $\begin{array}{c}\text { Aprendizado de discentes } \\
\text { de curso de mecânica }\end{array}$ & $\begin{array}{c}\text { Vantagens competitivas } \\
\text { dinâmicas }\end{array}$ & $\begin{array}{c}\text { Instituição de Ensino } \\
\text { Técnico e Superior }\end{array}$ \\
\hline 01 & $\begin{array}{c}\text { Marketing e } \\
\text { varejo }\end{array}$ & $\begin{array}{c}\text { Aumento da satisfação de } \\
\text { consumidores do comércio } \\
\text { de Erechim (RS) }\end{array}$ & $\begin{array}{c}\text { Vantagens competitivas } \\
\text { dinâmicas }\end{array}$ & $\begin{array}{c}\text { Instituição de Ensino } \\
\text { Técnico e Superior e } \\
\text { comunidade externa, }\end{array}$ \\
\hline
\end{tabular}

Fonte: SIGProj - IFRS Campus Erechim (RS), 2012.

Adaptação: Autores

Percebe-se que em 2012, assim como no ano anterior, os cinco projetos estão voltados para alavancar atividades econômicas da região por meio de vantagens competitivas

DRd - Desenvolvimento Regional em debate (ISSNe 2237-9029) 
dinâmicas, conforme as concepções e Albuquerque (2014), principalmente no setor de vestuário, difundido como elemento de dinamização e inovação da econômica regional. Além do ensino técnico, questões culturais e de inclusão social também passam a ser abordadas nas pesquisas, ou seja, une-se o desenvolvimento sociocultural às necessidades econômicas e mercadológicas da região, visando um desenvolvimento mais integrado e em conformidade com as determinações teóricas de Oprițescu (2012).

Os projetos também vêm aprimorar os instrumentos didáticos utilizados nos cursos, com o objetivo de melhorar a formação de recurso humanos e proporcionar conhecimento de novas tecnologias, empregadas aos diferentes segmentos aplicados na região, visando um desenvolvimento mais integrado, conforme relata a dimensão teórica de Lima e Simões (2009). Da mesma forma que em 2011, os projetos foram trabalhados de forma individualizada sem conexão entre si e não tiveram êxito na formação de redes interorganizacionais formais, apesar da existência de potencial para essa forma de organização, o que contribuiria para novas e complexas relações entre as organizações e os múltiplos atores que compõem o ambiente em que estão inseridas, conforme afirmam Loyola; Moura (1996), Siqueira (2000), Amato Neto (2005) e Balestrin (2002). Os projetos de pesquisas desenvolvidos em 2013 estão no quadro 4.

Quadro 4 - Projetos de Pesquisa cadastrados no SIGProj - 2013

\begin{tabular}{|c|c|c|c|c|}
\hline $\begin{array}{c}\text { Quanti- } \\
\text { dade }\end{array}$ & $\begin{array}{c}\text { Modalidade } \\
\text { do Projeto }\end{array}$ & Potencialidades & $\begin{array}{c}\text { Vetores de } \\
\text { desenvolvimento regional }\end{array}$ & $\begin{array}{c}\text { Vínculo do Projeto com a } \\
\text { Região }\end{array}$ \\
\hline 03 & Inovação & $\begin{array}{c}\text { Aplicação em cadeias } \\
\text { de produção industriais, } \\
\text { inclusive fora da região }\end{array}$ & $\begin{array}{c}\text { Vantagens competitivas } \\
\text { dinâmicas }\end{array}$ & $\begin{array}{c}\text { Instituição de Ensino } \\
\text { Técnico e Superior cadeia } \\
\text { industrial }\end{array}$ \\
\hline 01 & $\begin{array}{c}\text { Diversifica- } \\
\text { ção } \\
\text { econômica } \\
\text { regional }\end{array}$ & $\begin{array}{c}\text { Potencialidades de } \\
\text { desenvolvimento de } \\
\text { cadeia econômica com } \\
\text { plantas aromáticas }\end{array}$ & $\begin{array}{c}\text { Vantagens competitivas } \\
\text { territoriais }\end{array}$ & $\begin{array}{c}\text { Instituição de Ensino } \\
\text { Técnico e Superior e } \\
\text { indústria de perfumaria }\end{array}$ \\
\hline
\end{tabular}

Fonte: SIGProj - IFRS Campus Erechim (RS), 2013.

Adaptação: Autores

Além dos aspectos observados nos anos anteriores os projetos mostram maior potencialidade na dimensão científica tecnológica, voltada à inovação (variável aportada por Etzkowitz 2009, como um elemento propulsor de desenvolvimento), fator determinante para o desenvolvimento regional ao estimular o processo continuado de inovações nas cadeias de produção, conforme prezam Nakano, 2005; Fischer, 2004 e Serra; Rolim, 2013. Os quatro projetos cadastrados em 2013, tratam de experimentos capazes de agregar valor à produção, e em sua maioria, não se direcionam apenas às atividades desenvolvidas na região, mas em atividades industriais, portanto, mostra a condição do IFRS de contribuir com a dinâmica econômica de outras regiões e normalmente esta difusão acontece pelos egressos, quando advindos e projetados para outras regiões (FERNANDES, 2007).

Também se observa que as pesquisas procuram aportar para a integração de novas dinâmicas econômicas, neste caso, vinculada às plantas aromáticas regionais, portanto, foca em as vantagens competitivas territoriais, expostas por Albuquerque (2014) no referencial teórico e no aproveitamento das potencialidades regionais, conforme mencionaram Serra; Rolim (2013). Em cenário futuro podem converter-se em vantagens competitivas dinâmicas, contribuindo para a diversificação das atividades econômicas regionais, conforme Albuquerque (2014). Neste ano também não houve a formação de redes interorganizacionais.

DRd - Desenvolvimento Regional em debate (ISSNe 2237-9029) 
Em 2014, com a maior consolidação da instituição na região ocorreu uma maior produção de pesquisas desenvolvidas no campus, conforme pode ser observado no quadro 5.

Quadro 5 - Projetos de Pesquisa cadastrados no SIGProj - 2014

\begin{tabular}{|c|c|c|c|c|}
\hline $\begin{array}{l}\text { Quanti- } \\
\text { dade }\end{array}$ & $\begin{array}{l}\text { Modalidade } \\
\text { do Projeto }\end{array}$ & Potencialidades & $\begin{array}{c}\text { Vetores de } \\
\text { desenvolvimento regional }\end{array}$ & $\begin{array}{l}\text { Vínculo do Projeto com a } \\
\text { Região }\end{array}$ \\
\hline 03 & $\begin{array}{l}\text { Planejamen- } \\
\text { to e } \\
\text { viabilidade } \\
\text { de atividades } \\
\text { industriais }\end{array}$ & $\begin{array}{l}\text { Viabilidade e vantagens } \\
\text { competitivas das } \\
\text { atividades industriais e } \\
\text { diversificação das } \\
\text { atividades econômicas }\end{array}$ & $\begin{array}{c}\text { Políticas fundamentais de } \\
\text { desenvolvimento regional; } \\
\text { Vantagens competitivas } \\
\text { dinâmicas; Redes } \\
\text { Interorganizacionais }\end{array}$ & $\begin{array}{c}\text { Instituição de Ensino } \\
\text { Técnico e Superior e cadeia } \\
\text { industrial }\end{array}$ \\
\hline 06 & Inovação & $\begin{array}{c}\text { Aumento de } \\
\text { competitividade de } \\
\text { cadeia de produção } \\
\text { industrial e } \\
\text { agroindustrial } \\
\end{array}$ & $\begin{array}{l}\text { Vantagens competitivas } \\
\text { dinâmicas; Vantagens } \\
\text { competitivas territoriais; } \\
\text { Redes Interorganizacionais }\end{array}$ & $\begin{array}{l}\text { Instituição de Ensino } \\
\text { Técnico e Superior e cadeia } \\
\text { industrial e agroindustrial }\end{array}$ \\
\hline 02 & $\begin{array}{l}\text { Comporta- } \\
\text { mento do } \\
\text { consumidor } \\
\text { e inclusão } \\
\text { social }\end{array}$ & $\begin{array}{l}\text { Compreensão do } \\
\text { consumidor, inclusão } \\
\text { de pessoas com } \\
\text { deficiência }\end{array}$ & $\begin{array}{c}\text { Vantagens competitivas } \\
\text { dinâmicas }\end{array}$ & $\begin{array}{c}\text { Instituição de Ensino } \\
\text { Técnico e Superior, } \\
\text { consumidores e deficientes }\end{array}$ \\
\hline 02 & $\begin{array}{c}\text { Pesquisas } \\
\text { teóricas }\end{array}$ & $\begin{array}{c}\text { Análise de teorias de } \\
\text { desenvolvimento } \\
\text { regional }\end{array}$ & $\begin{array}{c}\text { Vantagens competitivas } \\
\text { dinâmicas }\end{array}$ & $\begin{array}{l}\text { Instituição de Ensino } \\
\text { Técnico e Superior }\end{array}$ \\
\hline 03 & $\begin{array}{c}\text { Dinâmicas } \\
\text { das cadeias } \\
\text { de produção }\end{array}$ & $\begin{array}{c}\text { Análise das } \\
\text { capacidades dinâmicas } \\
\text { das organizações, } \\
\text { inclusive quanto à } \\
\text { sustentabilidade }\end{array}$ & $\begin{array}{l}\text { Vantagens competitivas } \\
\text { dinâmicas e Vantagens } \\
\text { competitivas territoriais }\end{array}$ & $\begin{array}{l}\text { Instituição de Ensino } \\
\text { Técnico e Superior, } \\
\text { indústria têxtil, } \\
\text { agroindústria e indústria }\end{array}$ \\
\hline
\end{tabular}

Fonte: SIGProj - IFRS Campus Erechim (RS), 2014.

Adaptação: Autores

Quanto aos vetores de desenvolvimento alavancados pelos dezesseis projetos, no ano de 2014, foram mais abrangentes, além das vantagens competitivas dinâmicas, predominantes na maioria dos projetos, outros contribuem com as políticas fundamentais de desenvolvimento regional, dispostas por Llorens (2001) como favoráveis a criação de um "entorno territorial inovador" (ver Nakano, 2005). Além disso, neste ano também houve, a partir dos projetos, a interação da instituição com os atores sociais regionais e o fortalecimento das vantagens competitivas territoriais.

Dos projetos cadastrados em 2014, onze tiveram a contemplação de atores sociais da região, o que representa uma maior integração cooperativa e solidária da instituição com os membros do que atuam no território regional, conforme destaca Boisier (2006) em seus estudos sobre desenvolvimento. Estas interações, mesmo que de maneira informal, são capazes de promover aprendizado para ambas as partes, assegurando maior competitividade e sobrevivência destas organizações, na região.

Destacam-se os projetos do "Arranjo Produtivo Local - APL (grupo 01) como agregadores de valor para as empresas locais" e "abordagem sistêmica para o planejamento de aglomerações industriais" por seguirem a mesma linha de estudo e serem desenvolvidos por docente da área de moda e vestuário, que, no ano de 2013, teve participação ativa na elaboração da proposta do Arranjo Produtivo Local - APL Têxtil e Vestuário do Alto Uruguai 
Gaúcho - APL Polovest (SERRANO, 2013; ALBIQUERQUE, 2014). A proposta foi desenvolvida tendo como base a dissertação da referida docente e teve reconhecimento pela Agência Gaúcha de Desenvolvimento e Promoção do Investimento - AGDI/RS. O IFRSCampus Erechim faz parte dos 24 empreendimentos que oferecem apoio ao Arranjo (POLOVEST), que pode ser classificado como uma rede interorganizacional formal, embasada em potencialidades internas, conforme mencionaram Casarotto e Pires (2001). No ano de 2015 foram integrados novos projetos de pesquisa conforme pode ser verificado no quadro 6.

Quadro 6 - Projetos de Pesquisa cadastrados no SIGProj - 2015

\begin{tabular}{|c|c|c|c|c|}
\hline $\begin{array}{l}\text { Quanti- } \\
\text { dade }\end{array}$ & $\begin{array}{l}\text { Modalidade } \\
\text { do Projeto }\end{array}$ & Potencialidades & $\begin{array}{c}\text { Vetores de } \\
\text { desenvolvimento regional }\end{array}$ & $\begin{array}{l}\text { Vínculo do Projeto com a } \\
\text { Região }\end{array}$ \\
\hline 05 & $\begin{array}{l}\text { Desenvolvi- } \\
\text { mento } \\
\text { Regional }\end{array}$ & $\begin{array}{c}\text { Potencialização de } \\
\text { cadeias de produção e } \\
\text { diversificação das } \\
\text { atividades econômicas } \\
\text { regionais }\end{array}$ & $\begin{array}{l}\text { Políticas fundamentais de } \\
\text { desenvolvimento regional; } \\
\text { Vantagens competitivas } \\
\text { dinâmicas; Vantagens } \\
\text { competitivas territoriais }\end{array}$ & $\begin{array}{l}\text { Instituição de Ensino } \\
\text { Técnico e Superior e cadeia } \\
\text { agroindustrial e têxtil; } \\
\text { produtores rurais }\end{array}$ \\
\hline 08 & Inovação & $\begin{array}{c}\text { Dinamização dos } \\
\text { setores econômicos } \\
\text { com base na integração } \\
\text { de inovação e matéria } \\
\text { prima alternativa nos } \\
\text { processos produtivos }\end{array}$ & $\begin{array}{l}\text { Vantagens competitivas } \\
\text { dinâmicas; Vantagens } \\
\text { competitivas territoriais }\end{array}$ & $\begin{array}{l}\text { Instituição de Ensino } \\
\text { Técnico e Superior e cadeia } \\
\text { industrial alimentícia, } \\
\text { têxtil; mercado consumidor }\end{array}$ \\
\hline 02 & Educação & $\begin{array}{l}\text { Aprimoramento do } \\
\text { ensino e de modelo de } \\
\text { gestão de ensino } \\
\text { superior }\end{array}$ & $\begin{array}{c}\text { Vantagens competitivas } \\
\text { dinâmicas }\end{array}$ & $\begin{array}{l}\text { Instituição de Ensino } \\
\text { Técnico e Superior }\end{array}$ \\
\hline 01 & $\begin{array}{l}\text { Processo de } \\
\text { Gestão de } \\
\text { Produção }\end{array}$ & $\begin{array}{l}\text { Aprimoramento da } \\
\text { gestão rural vinculada } \\
\text { ao setor lácteo }\end{array}$ & $\begin{array}{c}\text { Vantagens competitivas } \\
\text { dinâmicas }\end{array}$ & $\begin{array}{l}\text { Instituição de Ensino } \\
\text { Técnico e Superior; } \\
\text { produtores rurais; } \\
\text { EMATER e ASCAR }\end{array}$ \\
\hline 02 & Marketing & $\begin{array}{l}\text { Aplicação do conceito } \\
\text { de design estratégico e } \\
\text { representações } \\
\text { corporais de mídia } \\
\text { impressa }\end{array}$ & $\begin{array}{c}\text { Vantagens competitivas } \\
\text { dinâmicas }\end{array}$ & $\begin{array}{l}\text { Instituição de Ensino } \\
\text { Técnico e Superior e } \\
\text { indústria têxtil e cosmética }\end{array}$ \\
\hline 02 & $\begin{array}{l}\text { Políticas } \\
\text { sociais e } \\
\text { cidadania }\end{array}$ & $\begin{array}{l}\text { Concretização dos } \\
\text { direitos fundamentais e } \\
\text { participação social na } \\
\text { gestão democrática }\end{array}$ & $\begin{array}{l}\text { Políticas fundamentais de } \\
\text { desenvolvimento regional }\end{array}$ & $\begin{array}{l}\text { Instituição de Ensino } \\
\text { Técnico e Superior e } \\
\text { políticas públicas } \\
\text { municipais }\end{array}$ \\
\hline
\end{tabular}

Fonte: SIGProj - IFRS Campus Erechim (RS), 2015.

Adaptação: Autores

Assim como nos anos anteriores, os vinte projetos desenvolvidos em 2015, o vetor de desenvolvimento regional mais promovido pelos estudos foi o de vantagens competitivas dinâmicas, existindo a interação da instituição com os atores sociais regionais sem a formação efetiva de redes interorganizacionas a partir deles, conforme evidencia estudos de Albuquerque (2014) e Fischer (2004). Os estudos beneficiam principalmente a área industrial no que diz respeito à inovação tecnológica e continuam sendo desenvolvidos de forma isolada, mantendo as mesmas facetas do papel da instituição para o desenvolvimento regional apresentada nos demais anos.

A análise geral dos projetos de pesquisa desenvolvidos e cadastrados no SIGProj do

DRd - Desenvolvimento Regional em debate (ISSNe 2237-9029) 
IFRS - Erechim (RS) demonstra que se voltam principalmente à competitividade das organizações deixam lacunas nos demais vetores considerados essenciais para o desenvolvimento local e regional, tais como das vantagens competitivas territoriais, as politicas fundamentais de desenvolvimento regional, as redes interorganizacionais e as redes de estruturas tangíveis e intangíveis são menos exploradas.

O IFRS apresenta forte interação com os atores sociais regionais, incentiva à aprendizagem, conhecimento coletivo e os projetos demonstram estar em sintonia com as atividades econômicas desenvolvidas na região, de forma menos intensa com os segmentos públicos (prefeitura municipal, autarquias e demais órgãos), desta forma, não é tão definidora na parceria de políticas públicas (PECI; COSTA, 2002). No entanto, em sua maioria, os projetos não formam vínculos capazes de se configurar ou promover redes e sim estudos isolados com a participação de algumas organizações da região, sem expressar uma liderança evidente tampouco à interatividade e integração interinstitucional, tão importante para o desenvolvimento da região, conforme evidenciado em estudos de Bologa (2010), Amato Neto (2005) e Casarotto; Pires (2001).

As principais facetas do papel do IFRS - Campus Erechim (RS) no desenvolvimento regional, por meio dos projetos de pesquisa, são principalmente: o desenvolvimento dos potenciais econômicos, a contribuição para o aumento da competitividade e a promoção do empreendedorismo e inovação, por vezes, de forma indireta, ficam restritas às pesquisas de suporte apresentadas por Fischer (2004), Cândido (2002), Etzkowitz (2009) e Fernandes (2007). Desenvolve-se pouco ou inexiste, o papel de combate às desigualdades regionais, mercantilização do conhecimento e de promoção da formação de redes formais e informais de desenvolvimento regional como atores institucionais.

No entanto, mesmo não envolvendo todas as condições necessárias para efetiva contribuição para o desenvolvimento regional, de acordo com o referencial teórico, o IFRS Campus Erechim (RS) apresenta evoluções na produção científica de pesquisa, no que diz respeito à abrangência dos projetos como propulsores do desenvolvimento regional. Em parte, este cenário pode ser explicado pela breve temporalidade da presença do IFRS, na região. Espera-se que com sua sedimentação também evolua quanto aos arranjos institucionais que promovem o desenvolvimento da região, com base nos efetivos resultados de suas ações canalizadas ao desenvolvimento, inclusive, evoluindo para a formação de redes interorganizacionais sólidas e contributivas para a consolidação socioeconômica, ambiental e institucional regional.

\section{CONSIDERAÇÕES FINAIS}

A partir das contribuições teóricas deste estudo, destaca-se que a educação é fatorchave para o desenvolvimento socioeconômico de países e de regiões. Nesse sentido, também se destaca o papel das redes interorganizacionais, no âmbito de atuação das instituições de ensino técnico e superior, como impulsionadores deste desenvolvimento.

No que diz respeito aos projetos de pesquisa cadastrados no SIGProj, não se verifica neles, ou a partir deles, a formação de redes interorganizacionais complexas até o momento.

DRd - Desenvolvimento Regional em debate (ISSNe 2237-9029) 
No entanto, os estudos, apesar de isolados, estão alinhados com o desenvolvimento das atividades econômicas locais e regionais e focam de diferentes formas na sustentabilidade das organizações da região.

Os projetos de pesquisa estão individualizados e com perspectivas de melhoria em cada segmento (propostas de intervenção) na perspectiva futura, ou seja, com base em seus resultados. Entretanto, praticamente não existe um "encadeamento entre os projetos de pesquisa", visando à formação de redes interorganizacionais, para o desenvolvimento regional, condição que pode ser revertida em período de tempo vindouro, com base em política institucional nesta direção.

Além do ensino técnico, questões culturais e de inclusão social também são abordadas nas pesquisas, ou seja, une-se desenvolvimento sociocultural às necessidades econômicas e mercadológicas da região. Os projetos também tratam de experimentos capazes de agregar valor à produção, não se direcionam apenas às atividades desenvolvidas na região, mas às atividades industriais de outros locais. Portanto, mostram a condição do IFRS de contribuir com a dinâmica econômica regional de outras regiões.

Os dados evidenciam também, a promoção prioritariamente das vantagens competitivas dinâmicas, ainda, a existência de ligações interorganizacionais, em parte, de maneira informal tanto com a iniciativa privada, instituições, órgãos públicos e comunitários (estes em menos escala), sendo que as ações de pesquisa com estes últimos dois grupos poderiam ser intensificadas. Por fim, ressaltam a participação do IFRS - Erechim (RS) no APL Polovest e a importância do arranjo para a região - este com rede constituída, em segmento produtivo que se amplia na região, portanto, que contribui para a diversificação dos sistemas de produção regional e evidencia o relevante papel da liderança da instituição de ensino em encontrar mecanismos autóctones de desenvolvimento com base em potencialidades já instaladas.

Conclui-se que, em nível institucional, o IFRS - Campus Erechim (RS) busca a integração de diversos atores em suas políticas de desenvolvimento, e, em nível de Estado, é parte integrante das políticas de desenvolvimento do governo federal. Verifica-se, então, que a organização está inserida em um ambiente no qual as redes fazem parte da sua constituição, organização e funcionamento. No entanto, a fase embrionária da atuação do IFRS de apenas seis anos, pode ser um limitador para a criação de redes interorganizacionais que promovam o desenvolvimento regional, mesmo se verificando a intensa interação (parte não formal) com os demais atores regionais.

\section{REFERÊNCIAS}

ALBURQUERQUE, F. Política regional y desarrollo territorial en América Latina y el Caribe. (Spanish). Informe Gepec, v. 18, n 2, p. 163-190, jul. 2014. Disponível em: $<$ http://web.b.ebscohost.com/ehost/pdfviewer/pdfviewer?vid=2\&sid=f59c5f14-7f07-41 ec95f7-6fce43f793b4\%40sessionmgr115\&hid=101>. Acesso em: 05 jul. 2017. 
AMARAL, M. G.; FERREIRA, A.; LACERDA, P. T. A inserção da universidade pública no processo de inovação e desenvolvimento regional: um estudo de caso exploratório. In: ENCONTRO DA ANPAD; 23. Anais do XXXIII Encontro da ANPAD, São Paulo, 2009.

AMATO NETO, J. Redes dinâmicas de cooperação e organizações virtuais. In: AMATO NETO, João (Org). Redes entre organizações: domínio do conhecimento e da eficácia operacional. São Paulo: Atlas, 2005, p. 17-38.

BALESTRIN, A.; VARGAS, L. M. Evidencias teóricas para a compreensão das redes interorganizacionais. In: ENCONTRO DE ESTUDOS ORGANIZACIONAIS, 2, 2002, Recife. Anais... Recife: Observatório da Realidade Organizacional: PROPAD/UFPE: ANPAD, 2002.

BISPO, F. C. S.; SANTOS JUNIOR, A. B. S. "Uma análise do Programa Universidade para Todos e sua relação com a democratização do acesso ao Ensino Superior e a redução de desigualdades regionais”. In: ENaNPAD, 37. Anais... Rio de Janeiro: ANPAD, 2013.

BOISIER, S. Desenvolvimento. In: SIEDENBERG, D. R. Dicionário desenvolvimento regional. Santa Cruz do Sul: EDUNISC, 2006, p. 69-70.

BOLOGA, G. Territorial competitiveness-form of existence of the quality of regional development. In: Lucrări Stiinifice, Universitatea de Stiinte Agricole Si Medicină Veterinară a Banatului, Timisoara, Seria I, Management Agricol, v. 2, n. 1, p. 127-134. Agroprint, 2010.

BOUCHER, G.; CONWAY, C.; VAN DER MEER, E. Tiers of engagement by universities in their region's development. Regional Studies. v. 37, n. 9, p. 887-897, dez. 2003. Disponível em: $<$ http://donorth.co/appurtenancy/pdfs/uni_engagement_reg_devel.pdf $>$. Acesso em: 28 abr. 2016.

\section{BRASIL. I Conferência Nacional de Desenvolvimento Regional: Documento de} Referência. Brasília, SDR/MI, 2012. 77 p. Disponível em: $<01 \mathrm{http}: / /$ www.integracao.gov.br/c/document_library/get_file?uuid=54bce099-503a-40768613-d90dd6107c79\&groupId=10157>. Acesso em: 01 mar. 2016.

Lei n. 11.892, de 29 de dezembro de 2008: Institui a Rede Federal de Educação Profissional, Científica e Tecnológica, cria os Institutos Federais de Educação, Ciência e Tecnologia, e dá outras providências. Diário Oficial da União, Brasília, DF, 30 dez. 2008. Disponível em: http://www.planalto.gov.br/ccivil_03 /_ato2007-2010/2008/lei/111892.htm. Acesso em: 05 maio 2016.

CÂNDIDO, G. A. A formação de redes interorganizacionais como mecanismo para geração de vantagem competitiva e para promoção do desenvolvimento regional: o papel do Estado e das políticas públicas neste cenário. READ - Revista Eletrônica da Administração. (UFRGS), Porto Alegre, RS, v. 28, n. 8, p. 32-47, 2002. Disponível em: $<$ http://seer.ufrgs.br/index.php/read/issue/view/2203>. Acesso em: 01 jul. 2016.

CASAROTTO FILHO, N. e PIRES, L. H. Redes de pequenas e médias empresas e desenvolvimento local. São Paulo: Atlas, 2001. 
CASTELLS, M. Local and global: cities in the network society. Tijdschrift voor economische en sociale geografie, v. 93, n. 5, p. 548-558, 2002.

DIAS, L. C. Os sentidos da rede. In: DIAS, L. C.; SILVEIRA, R. L. L. (Org.). Redes, sociedades e territórios. 1.ed. Santa Cruz do Sul: EDUNISC, 2005, p. 11-28. v. 1.

ESSER, K. et al. Competitividade sistemática competitividad internacional de las empresas y políticas requeridas. Berlim: Instituto Aleman de Desarollo. 1994. Disponível em: $<$ http://www.bocc.uff.br/pag/eiro-gomes-mafalda-duarte-joao-publicos-relacoespublicas.pdf $>$. Acesso em: 25 jun. 2016.

ETZKOWITZ, H. Hélice-tríplice: universidade-indústria-governo: inovação em ação. Porto Alegre: EDIPUCRS, 2009.

FERNANDES, R. G. T. Impactos locais e regionais da Universidade do Porto. 2007. 137 p. Dissertação (Mestrado em Economia) Universidade do Porto, 2007. Disponível em:

$<$ http://repositorio-aberto.up.pt/handle/10216/7560>. Acesso em: 26 mar. 2016.

FLEURY, S.; OUVERNEY, A. M. Gestão de redes: a estratégia de regionalização da política de saúde. Rio de Janeiro: FGV, 2007.

FURTADO, C. Introdução ao desenvolvimento: enfoque histórico-estrutural. Rio de Janeiro: Paz e Terra, 2000.

GODOY, A. S. Introdução à pesquisa qualitativa. Revista de Administração de Empresas, São Paulo, v. 35, n. 2, p. 57-63, 1995.

LIMA, A. C. C.; SIMÕES, R. F. Teorias do desenvolvimento regional e suas implicações de política econômica no pós-guerra: o caso do Brasil. Belo Horizonte: UFMG/Cedeplar, 2009.

LLORENS, F. A. Desenvolvimento econômico local: caminhos e desafios para construção de uma nova agenda política. Rio de Janeiro: BNDES, 2001.

LOYOLA; MOURA, S. Análise de redes: uma contribuição aos estudos organizacionais. In: FISCHER, T. (org.). Gestão estratégica: cidades estratégicas e organizações locais. Rio de Janeiro: Getúlio Vargas, 1996, p. 53-68.

MACULAN, A. M.; MELLO, J. M. C. University start-ups for breaking lock-ins of the Brazilian economy. Science and Public Policy, v. 36, n. 2, p. 109-114, mar. 2009. Disponível em: <http://www.proppi.uff.br/portalagir/sites/default/files/

AM_JM_UniDev_SPP_March09_Brazil.pdf>. Acesso em: 28 abr. 2016.

MINAYO, M. C. S. (Org.). Pesquisa social: teoria, método e criatividade. 29.ed. Petrópolis, RJ: Vozes, 2010.

MORAIS, A.; FERNANDES, P. O. Assimetrias regionais na região Norte de Portugal: uma análise de cluster. In: CONGRESSO DA APDR; 17. 2011, Bragança. Anais.... Bragança, 2011.

DRd - Desenvolvimento Regional em debate (ISSNe 2237-9029) 
OPRIȚESCU, E. M. et al. Competitiveness in regional development. Of the University of Petrosani Economics, 2012, p. 169.

PECI, A.; COSTA, F. J. L. Redes para implementação de políticas públicas: obstáculos e condições de funcionamento. In: ENCONTRO ANUAL DA ASSOCIAÇÃO NACIONAL DE PÓS-GRADUAÇÃO E PESQUISA EM ADMINISTRAÇÃO (EnANPAD); 26, 2002, Salvador. Anais... Salvador: ANPAD, 2002.

PERROUX, F. A economia do século XX. Tradução J. L. de F. Herder. Lisboa, 1967.

RESENDE, G. M. Elementos do desenvolvimento regional: temas atuais, desafios e oportunidades da questão regional. In: SILVEIRA, R. L. L. da (Org.). Observando o desenvolvimento regional brasileiro: processo, políticas e planejamento. Santa Cruz do Sul: Edunisc, 2013, p. 46-71.

ROSA, J. A. Planejamento estratégico do Alto Uruguai Gaúcho: construindo uma visão de futuro. Alto Uruguai, Erechim, RS: Graffoluz, 2008.

SEN, A. Desenvolvimento como liberdade. São Paulo: Companhia das Letras, 2000.

SERRA, M.; ROLIM, C. Desenvolvimento e engajamento regional: o papel das universidades. In: SILVEIRA, R. L. L. da (Org.). Observando o desenvolvimento regional brasileiro: processo, políticas e planejamento. Santa Cruz do Sul: Edunisc, 2013, p. 72-88.

SERRANO, R. Utilização do pensamento sistêmico e planejamento por cenários em setores produtivos: uma aplicação no setor de vestuário na região do Alto Uruguai.

Dissertação (Mestrado em Engenharia da Produção e Sistemas) - Programa de Pós-Graduação em Engenharia da Produção e Sistemas, UNISINOS, 2013.

SIQUEIRA, M. M. Redes sociais na gestão de serviços urbanos. Revista de Administração Pública, v. 34, n. 6, p. 179-198, 2000.

TRIVIÑOS, A. N. S. Introdução à pesquisa em ciências sociais: a pesquisa qualitativa em educação. São Paulo: Atlas, 2011.

YIN, R. K. Estudo de caso: planejamento e métodos. 4.ed. Porto Alegre: Bookman, 2010.

Artigo recebido em: 07/11/2018

Artigo aprovado em: 11/12/2018

Artigo publicado em: 19/02/2019

DRd - Desenvolvimento Regional em debate (ISSNe 2237-9029) 